Unless the adverse effects of $\mathrm{CMF}$ are recognised and combated its potential benefit on survival will not be fully realised.

This work was supported by the North-west Regional Health Authority.

1 Bonnadonne G, Brusamolino E, Valagussa P, et al. Combination chemotherapy as an adjuvant treatment in operable breast cancer. $N$ Engl $\mathcal{F}$ Med $1976 ; 294: 405-10$.

${ }^{2}$ Cooper AF, McArdle CS, Russel AR, Smith DC. Psychiatric morbidity associated with adjuvant chemotherapy following mastectomy for breast cancer. Br $\mathcal{F}$ Surg 1979;66:362.

3 Wing JK, Nixon J, Mann A, Leff JP. Reliability of the PSE used in a population study. Psychol Med 1977;7:505-16.

4 Maguire P, Tait A, Brooke M. Emotional aspects of mastectomy: a conspiracy of pretence. Nursing Mirror 1980 Jan 10:17-9.

(Accepted 18 August 1980)

University Department of Psychiatry, Withington and Christie

Hospitals, Manchester 20

G P MAGUIRE, FRCPSYCH, senior lecturer

A TAIT, SRN, research nurse

$M$ BROOKE, SRN, research nurse

C THOMAS, MRCPSYCH, senior registrar

University Department of Surgery

J M T HOWAT, FRCs, lecturer

R A SELLWOOD, FRCS, professor

Cancer Research Campaign, Department of Medical Oncology

H BUSH, PHD, MRCP, senior lecturer (now professor of oncology and director, Ontario Cancer Research and Teaching Foundation, Victoria Hospital, London, Ontario, Canada)

\section{Dapsone-induced optic atrophy and motor neuropathy}

Blindness is one of the most serious side effects of treatment with drugs. We report a case of a young man who became blind and developed weakness of the legs after inappropriate use of dapsone. This is the first report of optic atrophy in association with dapsone.

\section{Case report}

A 20-year-old healthy Sudanese man was convinced that a lipoma on his shoulder was a lepromatous nodule. To cure his "leprosy" he took dapsone $600 \mathrm{mg}$ daily for 10 days. Eleven days later he was admitted to hospital with vomiting, dizziness, and blurred vision. He looked ill and had cyanotic mucous membranes. No other physical abnormalities were noted. Dapsone poisoning was diagnosed, though tests for methaemoglobinaemia were not done. His condition improved when he was treated with fluid replacemen and ascorbic acid. Two days later he was completely well and was discharged. $\mathrm{He}$ was told not to take dapsone and reassured that he did not have leprosy.

He returned three days later with blurred vision, generalised muscular pains, and difficulty in climbing stairs. He denied taking dapsone or any othe drugs since discharge from hospital. Visual acuity was reduced in both eye to counting fingers only. There was bilateral restriction of peripheral visual fields. Haemorrhages and exudates were present in both fundi, but the optic discs were normal. There were no other cranial nerve lesions. He had severe weakness in both legs and obvious foot drop on the left. Tendon reflexes were symmetrically decreased in the legs, but plantar reflexes were normal. There was no sensory deficit.

Results of laboratory tests on second admission were: haemoglobin concentration $14.8 \mathrm{~g} / \mathrm{dl}$, white blood cell count $5.4 \times 10^{9} / 1\left(5400 / \mathrm{mm}^{3}\right)$, and erythrocyte sedimentation rate $3 \mathrm{~mm}$ in first $\mathrm{h}$. No reticulocytes were seen and the red-cell sickling test gave a negative result. Results of cerebrospina fluid examination and liver function tests were normal, as were fasting blood sugar concentration and concentrations of plasma urea and electrolytes.

Dapsone-induced motor neuropathy was diagnosed, and this drug was also considered as a cause of his blindness. A month after admission the visual loss persisted and both optic discs became pale, suggesting optic atrophy. Some of the exudates and haemorrhages, however, had cleared. Neither vision nor weakness showed any improvement during six months of follow-up.

\section{Comment}

The predominantly motor peripheral neuropathy, absence of sensory features, and clear drug history strongly incriminate dapsone.
Dapsone-induced peripheral neuropathy is well recognised, though the mechanism is unknown and diagnosis is based largely on history and examination. ${ }^{1}$ In common with some reported cases our patien has not shown improvement after stopping dapsone. ${ }^{2}$

Dapsone was stopped five days before the onset of blindness and weakness, though the dosage of dapsone was much higher than normal

In our patient retinal haemorrhages and exudates were seen on the second admission. Pale optic discs suggesting optic atrophy developed gradually, without preceding optic neuritis or papillitis. Optic atrophy has not been reported in association with dapsone. Brain haemorrhages and thrombosed vessels, however, have been noted at necropsy in fatal case of dapsone poisoning, ${ }^{3}$ and peripheral gangrene has occurred after administration of high doses of dapsone. ${ }^{4}$ We therefore suggest that a vascular process may have caused the optic atrophy.

The absence of cerebellar and long-tract signs, the development of optic atrophy without preceding optic neuritis, and the tropical environment make multiple sclerosis extremely unlikely. Repeated clinical and laboratory examinations have not detected parasitic or other infections.

We believe that dapsone should be included with disulfiram, chloroquine, and clioquinol ${ }^{5}$ as a cause of peripheral nerve damage and optic atrophy, though the risk of optic atrophy may be related to large doses of dapsone.

We thank Mr Hadi A El Sheikh, consultant ophthalmologist, the Eye Hospital, Khartoum, for his advice, and Miss Gillian Crease for typing the manuscript.

${ }^{1}$ Gutmann L, Martin JD, Welton W. Dapsone motor neuropathy-an axonal disease. Neurology 1976;26:514-6.

${ }^{2}$ Malkinson FD, Pearson RW. Year book of dermatology. Chicago: Year Book Medical, 1977:122.

${ }^{3}$ Davies R. Fatal poisoning with Udolac (diaminodiphenyl sulphone). Lancet $1950 ; \mathrm{i}: 905$.

4 Shelley WB, Goldwein MI. High dose dapsone toxicity. $\mathrm{Br} \mathcal{F}$ Dermato $1976 ; 95: 79-82$.

${ }^{5}$ Davies DM. Textbook of adverse drug reactions. Oxford: Oxford University Press, 1977:304-23.

(Accepted 27 August 1980)

Department of Medicine, University of Khartoum, PO Box 102, Khartoum, Sudan

M HOMEIDA, MD, MRCP, lecturer in medicine and consultant physician A BABIKR, MB, BS, medical registrar

T K DANESHMEND, MB, MRCP, visiting research assistant (now honorary medical registrar, University Department of Medicine, Bristol Royal Infirmary, Bristol BS2 $8 \mathrm{HW}$ )

\section{Rifampicin-associated pseudomembranous colitis}

Pseudomembranous colitis has been associated with most antimicrobial agents except antituberculous drugs. Rifampicin may not be immune, ${ }^{1}$ though the diagnostic criteria in the only case reported did not prove the involvement of Clostridium difficile. We report a further case of pseudomembranous colitis, apparently related to the administration of rifampicin.

\section{Case report}

A 60 -year-old man, who had previously been given only phenoxymethylpenicillin, was admitted to hospital with tuberculous meningitis. He was treated with isoniazid, ethambutol, and streptomycin for one week and then with isoniazid, ethambutol, and rifampicin. After two weeks he was given nystatin, flucloxacillin, and gentamicin for one week for intercurrent infections and then dexamethasone $12 \mathrm{mg} /$ day for one week, after which it was gradually withdrawn over about five weeks. Diarrhoea developed one week after nystatin, flucloxacillin, and gentamicin were stopped and soon after the initial dose of dexamethasone had been halved. The diarrhoea resolved after three days but recurred five weeks later, when dexamethasone was withdrawn. Pseudomembranous colitis was diagnosed and histologically confirmed after two weeks. Rifampicin was stopped, dexamethasone was restarted in low dosage, and he was given two one-week courses of vancomycin $2 \mathrm{~g}$ by mouth daily separated by one week, during which his diarrhoea returned. Sigmoidoscopic appearances were unchanged after one week but almost normal after two weeks. The diarrhoea settled within three weeks and did not return. 
Fresh stools or biopsy specimens were analysed for $\mathrm{Cl}$ difficile or its toxin, as described elsewhere. ${ }^{3}$ Isolates were identified by standard methods. Minimum inhibitory concentrations of several antibiotics were determined by inoculating $10^{4}$ colony-forming units on DST (Oxoid CM 261) plus $6 \%$ saponin-lysed horse blood, containing appropriate concentrations of antibiotic. Cl difficile $10^{4} / \mathrm{g}$ wet weight of faeces was isolated on the day on which rifampicin was stopped and not thereafter in three samples taken after the first course of vancomycin, in faeces and biopsy material collected during the relapse of diarrhoea, or in two samples of faeces collected during the second course of vanomycin. No toxin was detected in the only stool examined but the $\mathrm{Cl}$ difficile was toxigenic in vitro. The isolate of $\mathrm{Cl}$ difficile was resistant to tetracycline $(64 \mathrm{mg} / \mathrm{l})$, erythromycin $(>64 \mathrm{mg} / \mathrm{l})$, and rifampicin $(>100$ $\mathrm{mg} / \mathrm{l})$, and relatively resistant to penicillin $(4 \mathrm{mg} / \mathrm{l})$ and clindamycin $(2 \mathrm{mg} / \mathrm{l})$, but was sensitive to metronidazole $(0.5 \mathrm{mg} / \mathrm{l})$ and vancomycin $(2 \mathrm{mg} / \mathrm{l})$.

\section{Comment}

Although toxin was not detected in the faeces, this case shows all the features of pseudomembranous colitis, including the isolation of toxigenic $\mathrm{Cl}$ difficile during the episode of colitis but not after the successful use of vancomycin. The proof of the role of rifampicin was complicated by the administration of other antibiotics. During the three months before the patient developed colitis he received eight antibiotics, but all except isoniazid, ethambutol, and rifampicin were stopped at least six weeks before he developed diarrhoea-a much longer period of latency than is usually accepted. ${ }^{5}$ It seems unlikely that dexamethasone would have suppressed the disease. Rifampicin is the only one of the three remaining drugs likely to have been responsible, since neither isoniazid nor ethambutol has a significant effect on the large bowel flora. Furthermore, the isolate of $\mathrm{Cl}$ difficile was resistant to rifampicin. Although this resistance has not previously been reported, ${ }^{2}$ it probably emerged during rifampicin treatment.

This case very much strengthens the argument for including rifampicin in the list of antibiotics that cause pseudomembranous colitis.

We thank Professor P H Sönksen and Dr C Lowy for permission to report this case, and Miss $C$ Warren for determinations of minimum inhibitory concentrations. SPB thanks Upjohn Ltd for support.

1 Fournier G, Orgiazzi J, Lenoir B, Dechavanne M. Pseudomembranous colitis probably due to rifampicin. Lancet $1980 ; \mathrm{i}: 101$.

2 Acocelli G, Arioli V. Pseudomembranous colitis and rifampicin. Lancet $1980 ; \mathrm{i}: 827-8$.

s Larsen HE, Price AB, Honour P, Borriello SP. Clostridium difficile and the aetiology of pseudomembranous colitis. Lancet 1978;i:1063-6.

- Holdeman LV, Cato EP, Moore WEC. Anaerobe laboratory manual. 4th ed. Blacksburg, Virginia: Virginia Polytechnic Institute and StateUniversity Anaerobe Laboratory, 1977.

5 Anonymous. Antibiotic-associated colitis: a progress report. $\mathrm{Br} \mathrm{Med} \mathfrak{J}$ 1978 ;i:669-71.

(Accepted 2 September 1980)

Division of Communicable Diseases, Clinical Research Centre, Watford Road, Harrow, Middlesex HA1 3UJ

S P BORIELLO, BSC, research assistant

Departments of Medicine and Microbiology, St Thomas's Hospital Medical School, London SE1 7EH

R H JONES, MRCP, senior lecturer in medicine

I PHILLIPS, MD, MRCPATH, professor of microbiology

\section{Hypothermia: a possible side effect of prazosin}

Prazosin is a hypotensive agent which acts by reducing peripheral vascular tone. ${ }^{1}$ Its most important side effect is postural hypotension (first-dose phenomenon). ${ }^{2}$ We describe the case of a patient who became hypothermic after taking the drug.

\section{Case report}

A 60-year-old Surinam woman was admitted to hospital for treatment of hypertension. She had first been seen four years previously, when she presented with a raised erythrocyte sedimentation rate. One year later hypertension and mild renal failure with albuminuria were noted. Nephritis was diagnosed. She was given antihypertensive treatment, but she did not comply with the medication and was temporarily lost to follow-up. Later she

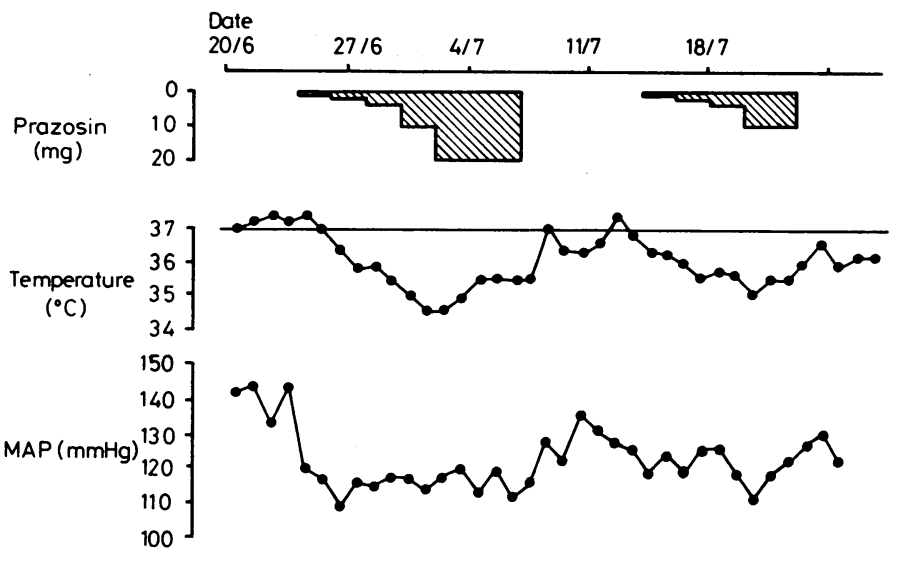

Changes in body temperature and blood pressure during treatment with prazosin.

returned to the outpatient department and was again found to have hypertension. On adriuission her blood pressure was $250 / 140 \mathrm{~mm} \mathrm{Hg}$ and she had a grade III hypertensive retinopathy. Otherwise, physical examination was unremarkable. Laboratory investigations showed: erythrocyte sedimentation rate $80 \mathrm{~mm}$ in first hour, anaemia (haemoglobin $5.5 \mathrm{mmol} / 1(8.86 \mathrm{~g} / \mathrm{dl}$ )), and renal failure (serum creatinine $350 \mu \mathrm{mol} / 1(3.95 \mathrm{mg} / 100 \mathrm{ml})$; creatinine clearance $16 \mathrm{ml} / \mathrm{min}$ ). A test for antinuclear antibody was negative but a trace amount of cryoglobulins was found.

The patient was treated with prazosin hydrochloride $0.5 \mathrm{mg}$ twice daily increasing gradually to $10 \mathrm{mg}$ twice daily. Before treatment her rectal temperature had been stable around $37^{\circ} \mathrm{C}$, but on the third treatment day it started to fall to reach a nadir on the ninth day (figure). Thereafter it remained stable at $35.6^{\circ} \mathrm{C}$. Extensive laboratory investigations showed no abnormality. Thyroid function was normal. Prazosin was stopped and her temperature rose again to normal within two days. One week later she was rechallenged with the drug and again her temperature dropped to $35^{\circ} \mathrm{C}$. The oral and skin temperatures changed in parallel with the rectal temperature. Prazosin was withdrawn and she was given propranolol and hydralazine, which controlled her hypertension equally well. Her body temperature has been normal ever since.

\section{Comment}

To our knowledge hypothermia has not been described as a side effect of prazosin. This case, however, shows that it may be. The hypothermia during the first treatment period could have been fortuitous, but the result of the second challenge strongly suggests that the drop in temperature was related to the drug. The hypothermia was unlikely to have been due to the reduction of blood pressure per se, since subsequent treatment with propranolol and hydralazine did not lower temperature but similarly lowered blood pressure.

The mechanism whereby prazosin could cause hypothermia remains unknown. The absence of shivering in our patient and the fact that core temperature fell argue against a purely peripheral cause. Therefore it probably resulted from depression of the hypothalamic thermoregulatory centre. Chlorpromazine, a drug with peripheral and central $\alpha$-blocking properties, also produces hypothermia, ${ }^{3}$ and the mechanism by which prazosin lowered body temperature in our patient may be similar. There is some experimental evidence that prazosin may exert a central action." A low body temperature in a patient being treated with prazosin should therefore alert the physician to this possible side effect.

${ }^{1}$ Lund-Johansen P. Hemodynamic changes at rest and during exercise in long-term prazosin therapy of essential hypertension. In: Cotton DWK, ed. Prazosin-evaluation of a new antihypertensive agent. Amsterdam: Excerpta Medica, 1974:43-54.

2 Stokes GS, Graham RM, Gain JM, Davis PR. Influence of dosage and dietary sodium on the first-dose effects of prazosin. $\mathrm{Br} M$ Med $\mathcal{F} 1977 ; \mathrm{i}$ : 1507-8.

${ }^{3}$ Reuler JB. Hypothermia: pathophysiology, clinical settings, and management. Ann Intern Med 1978;89:519-27.

4 Fuller RW, Snoddy HD, Perry KW. Effect of prazosin on norepinephrine concentration and turnover in rat brain and heart. Arch Int Pharmacodyn Ther $1978 ; 231: 30-41$.

(Accepted 15 September 1980)

Department of Internal Medicine, Zuiderzickenhuis, 3075 EA Rotterdam, The Netherlands

$P$ WE LEEUW, MD, physician

W H BIRKENHÄGER, MD, professor 